\title{
The "Pictorial Turn" as Crisis and the Necessity of a Critique of Visual Culture
}

\author{
Michele Bertolini \\ University Ca’ Foscari
}

\begin{abstract}
The "Pictorial” or "Iconic Turn" is a central issue in the contemporary theory of images and visual cultural studies. Should the theories concerning the "Iconic Turn" and formulated in the last 20 years by scholars such as Gottfried Boehm, William Mitchell, Hans Belting be taken as critical theories of crisis? Is the currently experienced "turn towards images” (and their progressive rehabilitation after a long standing philosophical and theological rejection) a sign and symptom of some crisis of people's relation with images, language and, generally speaking, with the representation forms of reality? The main hypothesis of this essay envisages two sets of problems: first, the analysis of the relation between the possible idea of turning point and the concept of crisis; secondly, the thorough investigation of the relation connecting the iconic turn to the project of "critical iconology" or "critique of visual culture," as outlined by Hans Belting and William Mitchell. From the interpretation of the "Iconic Turn” as situation of crisis and aesthetic, anthropological, and epistemological transformation follows the need for the sciences of image to provide a "critical iconology" in order to be able to theoretically reformulate the ideological and political presuppositions of some dominant contemporary forms of visual representation.

Keywords: visual cultural, crisis, critique, pictorial/iconic turn, iconophile/iconoclast doctrines, visual and verbal media, critical iconology.
\end{abstract}

\section{The "Pictorial Turn" between Crisis and Critique: An Introduction}

Within the realm of visual culture studies, art and images in general have been the object of critical and theoretical investigations leading to the shared acknowledgement of the contemporary era as the moment of an "Iconic Turn” (“ikonische Wende," as Gottfried Boehm says) or a "Pictorial Turn," which is urged by the proliferation of (traditional and digital) images within contemporary society as well as at several levels of the scientific and philosophical knowledge. Such an iconic turn marks an epistemological paradigm shift concerning the overall organization of knowledge and power, which is historically posterior to the "Linguistic Turn” codified by Richard Rorty in $1967 .^{1}$

My specific concern, here, may be formulated as follows: Should the theories concerning the "Iconic Turn” and formulated in the last 20 years by scholars such as Gottfried Boehm, William Mitchell, Hans Belting be taken as critical theories of crisis? Is the currently experienced "turn towards images" (and their progressive rehabilitation after a long standing philosophical and theological rejection) a sign and symptom of some crisis of people's relation with images, language and, generally speaking, with the representation forms of reality?

Michele Bertolini, Post-Doctoral Research, Department of Philosophy, University Ca' Foscari, Italy; main research field: Aesthetics, Philosophy of Art, and Theory of Images. Email: bertolinimichele@fastwebnet.it. 
From the interpretation of the "Iconic Turn" as situation of crisis and aesthetic, anthropological, and epistemological transformation-i.e., a new course with possibly liberating or destructive outcomes-follows the need for the sciences of image to provide a "critical iconology" (as also requested, besides Mitchell, also by Hans Belting), in order to be able to theoretically reformulate the ideological and political presuppositions of some dominant contemporary forms of visual representation. The adjective "critical" in the contemporary dialogue on images should then be investigated in its constitutional and complementary relation with the notions of "turning point" and "crisis." Similarly, also its philosophical role of emancipation and liberation from implicit presuppositions, which are often concealed by the power, speeches, and institutions overruling the relation between the contemporary subject and images, should be examined.

Within the realm of the recent proposals for a theory or science of images, the demand for a periodization of the several epochs or regimes of the Western gaze has been often accompanied by the acknowledgement by several scholars of some historical turning points in the human relation to images, which have been described as fractures, moments of crisis, breaking faults. A distinctive rhetoric of discontinuity and crisis permeates the methodologically and content-wise well differentiated studies of Hans Belting on the crisis of cult images ${ }^{2}$ as the great media-logical fractures of humanity (i.e., writing, printing, audio-visual) in Régis Debray's media-logical project defining three different continents of image (i.e., the idol, the art, the visual). ${ }^{3}$ Also Jonathan Crary's enquiries on the role of technique in the genesis of the observing subject of modernity apply a discontinuous model of historical explanation in opposition to the linear and progressive paradigm of the traditional history of technologies from the dark room to photography and cinema. Thus, the rise in the early 19th century of a model of subjective vision based on physiological optics entails the collapse and dismantling of the observer model channelled by the dark room and optical geometry, which was dominant in the 17 th and 18th centuries. ${ }^{4}$ According to Belting, the iconic turn giving way to the development of modern art during the Renaissance implies a crisis in the mode of reception and usage of religious images in the late Middle Ages. The emancipation of art as new cultural object presupposes the decline of the cult of images, and therefore not only the social crisis of a given technical production of images, but also the crisis and transformation of gazes and vision practices which intercept and experience images. Differently, Davis Freedberg's anthropological and comparative approach in The Power of Images, despite acknowledging the unavoidable influence of the historical and social context affecting the emotional and psychological relation between man and images, endorses the elements of continuity and similarity in the human attitude towards images, rather than those aspects of fracture and discontinuity. ${ }^{5}$ The historically recurrent and cyclic phenomena of iconoclasm and censorship or of devotion and fetishism in relation to images testify according to Freedberg the constant and real power of images as to evoke compassion, empathy, or indignation; such a power is likely to be intensified by digital photography, by the world-wide development of the web, and by the spreading of technological means for the reproduction of images. Thus an overall idea of virtually permanent "crisis" is profiled.

The main hypothesis of this essay envisages two sets of problems: first, the analysis of the relation between the possible abused idea of turning point and the concept of crisis; secondly, the thorough investigation of the relation connecting the iconic turn to the project of "critical iconology" or "critique of visual culture," as outlined by Mitchell in the last chapter of the 2005 book What do pictures want? Such an issue should allow the elucidation of the connection between crisis and critique. ${ }^{6}$ 


\section{The Return of the Images: A Comparison between Boehm and Mitchell}

Twenty years after the almost simultaneous publication in 1994 of Boehm's and Mitchell's essays introducing the terms "Iconic Turn" and "Pictorial Turn," the methodological and theoretical ground of the theory or science of images appears today more unstable and problematic than ever. One of the most discussed points in the new discipline concerns the claim of autonomy or independence of the logic and theory of images. Such a regulating and scientific autonomy is translated, according to some interpreters, in the autonomy of what is visual from what is linguistic, that is to say, the autonomy of the image from the word. Such an autonomy is presented as paradoxical since the very first pages of the foundational text Picture Theory by Mitchell, as it is claimed that the iconic turn does not simply and naively concern the current condition of domain and primacy of images in contemporary society, supported by the proliferation of digital means of reproduction-a debatable claim in itself-but it rather concerns a theoretical and scientific shift in people's relation to images. ${ }^{7}$ The iconic turn would then rather interest "the way one talks about images" (Boehm 2009), ${ }^{8}$ with the result that each science or theory of images would necessarily imply also a new philosophy of language concerning images. Verbal language is logically implied by the science of images, to the point of defining its "constitutive paradoxicality," as it has been already clear in its terminological choices: the metaphor of the "turn" (Wendung) selected by Boehm and Mitchell is indeed an image which recalls, next to the notion of "Paradigm Shift" of Thomas Kuhn, also "the Linguistic Turn" of Richard Rorty, in relation to which it claims to achieve a "dialectical” overcoming.

According to Gottfried Boehm, for instance, the critique of language performed by 20th century philosophers (from Husserl to Derrida, via Freud, Wittgenstein, and Heidegger) should result in its overcoming, that is to say, reach a critique of image, since precisely "the original linguistic dependency of every knowledge" finds in the metaphor, which is in the figurative power of language, and in the indicating gesture "the extralinguistic truth foundation of language propositions" (Boehm 2004). ${ }^{9}$ In the essay "The Return of the Images (Die Widerkehr der Bilder)," opening the volume edited by Boehm, What is an Image?, the turn towards the image "has its historical placement within Modern philosophy," as a rigorous position within the critical project of "self-foundation" of philosophy (Boehm 1994), ${ }^{10}$ which from Kant reaches Wittgenstein and Blumenberg, going through Nietzsche and Konrad Fiedler. The iconic turn sprouts up as an internal revolution within the radical questioning of logos, whose crisis shows the world of concepts' dependency on metaphors, which is on the figurative background of language. Boehm rightfully speaks of the turning point as of a return of the images, to which not only philosophical enquiries have contributed, but also the whole history of the theories of vision in the Nineteenth century with the essential participation of Modern art and especially 20th century avant-garde. The retrieval of some intuitive and figural basic ground-which has always belonged to the logos, although it has been hidden, concealed, left opaque-is fully achieved thanks to the new central position covered by the polysemy of metaphors as elucidated by Nietzsche in philosophy. The appearance of the image on the basic ground of language, as figural and metaphorical texture, recommends to the newly born science of images to pursue a dialectical genealogy (as defined by Boehm) or a conflictual and agonistic genealogy (as preferred by Mitchell) in relation to verbal language, as to articulate its autonomy on the network background of wider extra-iconic relations. The iconic turn would thus place itself at the crossroads between before and after, within a development, simultaneously as an answer and as a retrieval (a discovery which is also a return) concerning far reaching social and cultural phenomena. Such an articulation and perspectival 
opening is arguably very beneficial for different reasons, not least the possibility to avert sterile specialism, excluding the risky scenario in which the autonomy of the image loses the "commerce with the extra-iconic world," which is the source of "images' power" and "performative efficacy."11

According to both Boehm and Mitchell, the condition of crisis accompanying the iconic turn should be preserved from a reductive definition or an exclusively negative evaluation. Such a condition of crisis may be articulated on the historical level as a form of theological-political clash between iconophile and iconoclast positions without thereby being reduced to it. The crisis actually crosses the overall commerce of men with the universe of images as a transcendental underground stream. Any conflict concerning the value of images, at some point of history, as for instance the paradigmatic dispute between Moses and Aaron in the Old Testament, ${ }^{12}$ shows, according to Boehm, an internal articulation of the logic of images, which concerns the whole destiny of images beyond the historical contingency of the theological battles iconophiles against iconoclasts. Moses and Aaron personify two polar position, i.e., two permanent ways to understand images (as embodied presence according to Aaron, and as simple representation or pure sign according to Moses), which incessantly correspond to each other and call upon each other, thus deploying the whole range of the figurative potential of the image from ban to legitimation. ${ }^{13}$ In this respect, the condition of crisis does not actually define the temporary situation of fracture and anarchic overturning of some balance striving towards its overcoming; it rather reveals the intimate dimension of the dialectical conflict permeating the logic of images in itself. Such a dimension is defined by Boehm also as "iconic contrast," and is acknowledged by Mitchell as the agonistic dimension and permanent clash between visual representation and verbal representation in figurative arts as well as in literature. ${ }^{14}$

\section{The Rise of a “Scopic Regime:” Two Examples}

The dialectic articulation between the critique of language and the critique of the image prompts the interpreter towards a new historical and theoretical evaluation of those moments in the Western culture where a paradigmatic shift in the relation among knowledge, thought, and language triggered a perspectival change regarding the image. One may wonder, for instance, to what extent the rise of a given "scopic regime"-as in Martin Jay's words ${ }^{15}$ - within a new theoretical framework concerning visuality and the products of visual culture is linked to the critical transformation of the theoretical investigation of language and of the practice of language. Two examples may be recalled as to verify the adopted hypothesis. First, let's consider the revolution of ideas achieved by the Enlightenment, the critical era par excellence. The revolution was conveyed through words and in virtue of the transformation at several levels of the languages applied to knowledge and literature. Almost at the same time a revolution took place in philosophy and science regarding images, which led to the birth of aesthetics as philosophical discipline as well as to the rise of the first form of art critique exemplified by the pages of Paris' Salons.

In this respect, Diderot's path may be taken as paradigmatic, as it testifies to a philosophical and literary crisis resulting in the critique of art images (pictorial and theatrical in particular) ${ }^{16}$ As in a fruitful chiasma, one may find in Diderot's personal experience the crossing point between a critical approach to language and the renewing crisis concerning the relation to images. The gaze on images inaugurated by Diderot's art critique as well as by many of his contemporaries testifies indeed to the crisis of the relation between the image and the beholder and between the painting and its viewer. Both the artists, e.g., Greuze and later on also David, and the intellectuals are manifestly aware of the crisis. Diderot and Lessing found in aesthetics a moment of balance in 
the crisis, some sort of solution, although temporary, to the conflict, a troubled disciplinary peace; to the contrary, the crisis triggers Rousseau's refusal and full condemn of any artistic or theatrical imitation. ${ }^{17}$

In the historical-critical account outlined in Absorption and Theatricality: Painting and Beholder in the Age of Diderot, ${ }^{18}$ Michael Fried has described the genesis of the Modern gaze on artistic images within the dialectical relation between the intentions of 18th century artists and the theoretical instances explicated by aesthetics and the theory of art, thus circumscribing his proposal within the rigid framework of the historical-artistic research. According to Fried's perspective, in the second half of the 18th century and precisely through French painting, the elementary convention according to which paintings are made to be beheld can no longer be simply accepted, but it has to be discussed and neutralized through some strategies of representation defined as absorption painting or anti-theatrical painting. What is at stake here is, briefly, the neutralization or deposition of the beholder's gaze as symptomatic of mistrust regarding some images and representations. In other words, the beholder's gaze itself would entail the risk of artistic production drifting towards spectacular theatricalization. The subtly iconoclastic drives in the 18th century culture had for that matter a moment of radical expression and vandalic explosion during the French Revolution. ${ }^{19}$ Diderot's final stance in favour of images is actually the result of a severe critique and new definition of the status, role, and function of images in modern French society, which concern also painting, and should be conceived of within a more general and renovated awareness of the cultural and educational value of images. ${ }^{20}$ As Fried writes, emphasizing the iconoclast background on which the iconophile position is profiled,

the demand that painting defeat theatricality - that it establishes what I have called the supreme fiction or ontological illusion that the beholder did not exist, that there was no one standing before the canvas—placed the art of painting under tremendous pressure for the simple reason that paintings, more intensively and as it primordially than other class of artifacts, are made to be beheld. ${ }^{21}$ (Fried 2008, 26)

By interpreting the anti-theatrical gaze inaugurated by Diderot's Salons as the scopic regime of Modernity, i.e., as a turning point giving way to a new attitude towards artistic production and the world of images in general, it is possible to shed some light and provide a thorough analysis of the essential connection between the concepts of crisis, turn, and critique. The crisis in the relation between man and images, urged also by the social transformations caused by the development of the bourgeoisie public of the Salons, as well as by the new arrangements of the Eighteenth century art market, finally more independent from the control instances of the monarchy and of the academy, produces a new critical appreciation of images based on the new position of logos with respect to the iconic universe. The pivotal position of the concept of metaphor and expressive hieroglyph within Diderot's stance could be a further hint to the opening of though and language to their internal and constitutional iconic dimension. ${ }^{22}$

A second example, almost at the beginning of the 20th century, may be found in the person of Konrad Fiedler, whom Gottfried Boehm referred to as the late 19th century pioneer of the iconic turn. Fiedler put together his theory of the origin of the artistic figurative activity on the basis of his exclusive interest for the productive knowledge of the eye and the heuristic development of vision, regardless of verbal language. ${ }^{23}$ However, Fiedler's very theory, as already emphasized by Cassirer, was developed through a close dialectical confrontation with Humboldt's expressivist theory of language, according to which language is the continuous creation of new forms, energeia, and not only of ergon. From this dialogue, Fiedler could draw some enlightening hints in the direction of images thinking and of the autonomous productive and shaping abilities of 
sight. ${ }^{24}$ The separation between the realm of the visual and the realm of speech thus allows not only the clear assessment of images' autonomous meaning independently of words, but also the new setting for a comparison with verbal language based on the common symbolic function of representation of thoughts, which is equally accomplished by the two means of expression.

\section{A Paradigm Shift and a Recurrent Trope: Mitchell on "Pictorial Turn"}

The background crisis in which the "Pictorial Turn" sprouts out, as described by Mitchell, however, is not simply a theoretical issue pertaining to Humanities, which is an epistemic and perspectival paradigm shift in the assessment of an old question, such as that of the relation between man and images. Notably, in the letter exchange with Gottfried Boehm, first published in German in 2007 and edited by Hans Belting, which concerns the affinities and differences between the "Pictorial Turn" and the "Iconic Turn," Mitchell has made clear that the turn both concerns the paradigm shift in the branches of knowledge and the sphere of public culture: "There is no doubt that a pictorial turn has also occurred at the level of popular perception, in relation to new technologies of production, distribution, and consumption of images.” The crisis accompanying the iconic turns (plural, since the contemporary turn is just the last of a long series) arise, therefore, as "a 'recurrent trope,' that occurs when a new image-repertoire, or a new technology of image-production creates widespread anxiety, a kind of 'iconic panic,"” or as "the product of a social movement based in the fear of a new image" (Boehm 2010). ${ }^{25}$ Panic is often followed by the outburst of destructive actions against images. Hence, the crisis affects the "socially determined relation between the (production of) images, new technologies, and the far-reaching anthropological modifications entailed by these latter" (Cometa 2008). ${ }^{26}$ High culture and low culture are both actively involved in the processes of crisis preluding to the iconic turn, according to clearly interrelated dynamics which make the distinction between the two imprecise and ultimately fruitless. People's fear of images, on which their new appreciation is based, may be found as well in high theoretical speculations, as testified by the several episodes of philosophical iconoclasm from Antiquity to the present time. While Boehm conceives of the iconic turn as of a "return of images," within the framework of an historical and dialectical process mainly going through philosophy or at any rate through the privileged relationship between philosophy and art, Mitchell stresses on the troublesome and shifty nature of the object or objects of inquiry entailed by the pictorial turn, thus opening the investigation to a much wider dominion of images beyond the single field of artistic images. As Mitchell writes: "What makes for the sense of a pictorial turn, then, is not that we have some powerful account of visual representation that is dictating the terms of cultural theory, but that pictures form a point of peculiar friction and discomfort across a broad range of intellectual inquiry” (Mitchell 1994). ${ }^{27}$

Crisis, within Mitchell's perspective, defines therefore primarily the obscure, critical, problematic, conflictual relation, which is marked by fear and anguish, but also by desire and marvel, experienced by several societies with respect to images at some given crucial moments of their history. The moments of iconic turn are precisely the answer to a situation of crisis in the relation with images, often linked to euphoria and anxiety for the "new dominion" of the image. Such crisis stimulated a critical stand and the desire for new reflection and thematisation of a still obscure object. Finally, Mitchell claims that the very object of the new science of images is problematic. ${ }^{28}$ The pictorial turn should then be preserved from essentialist and univocal determinations, as to be the object of historical critique. Since it is a tropos, a figure of narrative and speech repeated several times since Antiquity - from the cult of the visible idol by the Jewish people refusing Moses' written law to Plato's condemn of images, from the clash between image and word in Lessing's 18th century Laocoön to the current 
debate on the dreaded proliferation of technologically reproducible images-the iconic turn is not a unique prerogative of the present time, but it is rather the symptom of a conflict on and about images that should be each time understood in its specific historical and social conditions. ${ }^{29}$

Secondly and more specifically, the "crisis" concerns the relation between words and images, that is to say, the situation of competition, conflict, fight, and clash that images and text put up one against the other, each time newly resetting the issue of comparison, reciprocal similarity, and difference. Each iconic turn is thus marked also by a theoretical rearrangement of the relation between language and images, as well as of the relations between sight and the other senses (notably hearing and touch). Such rearrangements lead to a “crisis," i.e., to opposite positions, extremely and naively positive critical judgments (the euphoria for the alleged hegemony of the visual), and negative apocalyptic judgements (iconoclasm stigmatizing the damages produced by the domain of the visual in contemporary societies). The very articulation word/image, according to Mitchell, should be reformulated by acknowledging its essentially dialectical features: Each term is opposed to itself and simultaneously incorporates the other, so that the issue word/image is "inside" the issue of image and vice versa. ${ }^{30}$ Such an internal difference, based on which the image encompasses the word within itself as soon as it takes position against it, works on two interconnected relational fields: the semiotic level and the level of sensory relations.

The iconic turn produced by visual studies is not free of that "fear of imagery lurking beneath every theory of imagery,"31 which Mitchell already emphasized in Iconology in 1987, his first important theoretical work, neither it is free of anxiety and suspicion concerning vision as pointed out by Martin Jay in Downcast Eyes. The Denigration of Vision in XX Century French Thought. ${ }^{32}$ According to Mitchell, the iconic turn is the critical interpreter of a kind of crisis that does not restrict itself to disorienting established disciplines pertaining to academia (primarily aesthetics and history of art), which are menaced by the rise of new branches of knowledge such as visual studies with uncertain scientific borders. The crisis ultimately matures and evolves within what has been defined by Mitchell as the "dialectical concept of visual culture."

The radical questioning of vision as natural attitude and the critique to the naturalistic fallacy, which simply reduces visuality to a universal and super-historical natural faculty, ${ }^{33}$ results in an idea of vision as cultural and social activity, as symbolic construction, which should however look back to its natural and biological features, paving the way to "an investigation of its non-cultural dimensions, its pervasiveness as a sensory mechanism that operates in animal organisms all the way from the flea to the elephant. This version of visual culture understands itself as the opening of the dialogue with visual nature” (Mitchell 2005). ${ }^{34}$ The visual culture should therefore constantly dialogue with the visual nature, which means not simply overcoming the prejudice on the alleged naturalness of seeing, but rather investigating such transparency as an issue that is still unsolved after the full acknowledgment of the linguistic and cultural references of seeing. Granted that vision is a language which is culturally and socially apprehended or even genetically transmitted, what cognitive, emotional, perceptual surplus does it offer in comparison with verbal language? What universality does it provide in relation to the local and national specificity of languages? The social construction of vision should be complemented by an investigation on the visual construction of society. Granted that people's way of beholding is the product of social interactions and cultural mediation, it is equally true that "our social arrangements take the forms they do because we are seeing animals" (Mitchell 2005). ${ }^{35}$ Within the framework of the profiled dialectical interaction, the crisis of the natural attitude towards vision is thoroughly developed by 
the critique of the visual culture, thus outlining the project of critical iconology, which is also the last point of this essay.

\section{Conclusion: The Project of Critical Iconology}

Mitchell's critical iconology is aimed at exposing and demystifying the proliferation of the myth and fetish of the "visual" and of "visual media." He thus attempts the analysis and explicit explanation of the historical and ideological causes leading to the claim of pure opticality concerning paintings and visual media, which disregards of how language and non-visual elements are inevitably entailed by perception of the so-called visual media. The antinomies of judgement, separating and opposing iconophiles and iconoclasts, or the supporters of the primacy of visual media against the supporters of the necessary kick back of verbal media, should be fully overcome by the critical attitude of visual culture. "Critique" here defines primarily, as it has been repeatedly stated by Mitchell, the strong desire that refuses to take the vision as granted, which insists on theorizing, critiquing, and historicizing the visual process as such, establishing " 'the visual' at the center of the analytic spotlight rather than treating it as a foundational concept that can be taken for granted" (Mitchell 2005). ${ }^{36}$ The critique of vision prevents the reification of the concept of visuality, as well as its a-problematic and a-critical endorsement as the sovereign sense of modernity, or even as scapegoat of the present evil. Visual culture should not restrict itself to the application of cultural studies to the realm of visuality, on the assumption that such visuality is not questioned, separated from its obvious immediacy and evidence, analysed in its natural and cultural, social, and biological components. Mitchell's project may be defined as a performative and educational program,

a kind of de-disciplinary exercise: visual culture starts out in an area beneath the notice of these disciplines (i.e., art history, aesthetics, media studies) - the realm of nonartistic, nonaesthetic, and unmediated or "immediate" visual images and experiences... a larger field of what I would call "vernacular visuality” or “everyday seeing."37 (Mitchell 2005, 356)

Precisely the critical process applied to visuality would allow visual culture "to get beyond these 'scopic wars' into a more productive critical space, one in which we would study the intricate braiding and nesting of the visual with the other senses, reopen art history to the expanded field of images and visual practices” (Mitchell 2005). ${ }^{38}$

Critical iconology should absorb the incentives provided by Panofsky's iconology by integrating them with a more complete investigation of the position of the beholder, on the nature of the gaze directed at the images, which should take into account the enquiry on the historical construction of several models of vision and spectatorship, and which should also be able to articulate a critical and mutual encounter between iconology and ideology. ${ }^{39}$ The critique of visual culture aims not only at making the science of images ideologically self-conscious and self-critical, but also at making ideology iconologically self-conscious. It should, then, not only shed light on the ideas enclosed in the images (the logos of the icon), but also free the images at the bottom of ideas, in other words, read the ideas as images, thus creating a double crossroad between the speaking subject and the observing subject. By avoiding the excesses of the rhetoric of crisis and system break down, Mitchell's proposal finally aims at establishing the right distance from the dominant discourse on the iconic turn, by placing the history of vision within the reconstruction of gaze's daily and concrete practices, ultimately avoiding the risk of outlining an idealistic history of visual culture. 


\section{Notes} 1967.

1. Richard Rorty, The Linguistic Turn: Recent Essays in Philosophical Method, The University of Chicago Press, Chicago,

2. Hans Belting, Likeness and Presence. A History of the Image before the Era of Art, Oscar Beck, München 1990.

3. Régis Debray, Life and Death of the Image. An History of the Western Gaze, Gallimard, Paris, 1992; ibid., "The Three Ages of Looking," Critical Inquiry, 21, 1995, 529-55.

4. Jonathan Crary, Techniques of the Observer. On Vision and Modernity in the 19th Century, MIT Press, Cambridge (Massachusetts) 1990. The preference of a historical paradigm of discontinuity and crisis, instead of a linear and continuity model, is according to Crary the result of a conscious political choice, which orientates our ability in interpreting the present time. A critical investigation of Crary's historical method is provided by William Thomas Mitchell, The Pictorial Turn, ibid., Picture Theory. Essays on Verbal and Visual Representation, The University of Chicago Press, Chicago-London, 1994, 11-34. The first edition of the essay “The Pictorial Turn” appeared on Art Forum, March 1992.

5. David Freedberg, The Power of Images. Studies in the History and Theory of Responses, The University of Chicago Press, Chicago, 1989.

6. William Thomas Mitchell, Showing Seeing: A Critic of Visual Culture, ibid., What do Pictures Want? The Lives and Loves of Images, The University of Chicago Press, Chicago and London, 2005, 336-56; Critique/Crisis: A Question in Cultural Studies, edited by Michele Cometa and Valentina Mignano, Quodlibet, Macerata, 2014.

7. William Thomas Mitchell, The Pictorial Turn.

8. Michele Di Monte, Maria Giuseppina Di Monte, "Introduction,” Gottfried Boehm, The Iconic Turn, edited by Michele Di Monte, Maria Giuseppina Di Monte, Meltemi, Roma 2009, 12 (my translation).

9. Gottfried Boehm, "Beyond the Language? Remarks on the Logic of the Images,” Iconic Turn. The New Power of Images, edited by Christa Maar and Hubert Burda, DuMont, Köln, 2004, 36-37 (my translation).

10. Ibid., "The Return of the Images”, What is an Image?, edited by Gottfried Boehm, Fink, München, 1994, 15.

11. Tonino Griffero, "Postface. The (Irresistible?) 'Career' of the Image,” Gottfried Boehm, The Iconic Turn, 288-9 (my translation).

12. Exodus 20.4.

13. Gottfried Boehm, “The Question of the Image,” What is an Image?, 325-43.

14. Also the relation between the visible dimension and the verbal one is, according to Mitchell, affected by opposite feelings, such as "hope," "fear," or "indifference," which are expressed by the several modes of approach to ekphrasis in relation with the other from itself, i.e., image: William Thomas Mitchell, Ekphrasis and the Other, ibid., Picture Theory. Essays on Verbal and Visual Representation, 151-81.

15. Martin Jay, “Scopic Regimes of Modernity,” Vision and Visuality, edited by Hal Foster, Bay Press, Seattle, 1988, 3-23.

16. Reinhart Koselleck in his famous book Kritik und Krise (1959) made reference to the Enlightenment's inability to thematize the political and moral concept of crisis, which is alien to the thinking model based on the idea of linear progress. Two decisive and important exceptions are nevertheless taken into account: Diderot, who expresses the idea of an internal dualism in man, and Rousseau, who foresees the revolution as a state of crisis, emphasizing the internal inconsistencies of the relation between State and society: Reinhart Koselleck, Critique and Crisis: Enlightenment and the Pathogenesis of Modern Society, Berg, Oxford, 1988.

17. Denis Diderot, Diderot on Art (Salon 1765 and Notes on Painting, Salon 1767), edited and translation by John Goodman, Introduction by Thomas Crow, Yale University Press, New Haven-London, 1995, Vol. 2; Gotthold Ephraim Lessing, Laocoon: An Essay on the Limits of Painting and Poetry, translated, with an introduction and notes by Edward Allen McCormick, The Johns Hopkins University Press, Baltimore (Maryland), 1984; Jean-Jacques Rousseau, Politics and the Arts: Letter to M. d'Alembert on the Theatre, translated, with notes and an introduction by Allan David Bloom, The Free Press, Glencoe, 1960.

18. Michael Fried, Absorption and Theatricality. Painting and Beholder in the Age of Diderot, The University of Chicago, Chicago-London, 1980.

19. Dario Gamboni, The Destruction of Art. Iconoclasm and Vandalism since the French Revolution, Reaktion Books, London, 1997.

20. Scholarly literature has recently addressed with increasing interest the topic of 18th century visual culture, mediated by the spreading of new optical devices and by the rising of new modes of observation, medical, scientific, juridical, aesthetic on bodies and visible phenomena: The Window of the Text. Literature and Vision Devises from 18th Century to 20th Century, edited by Valeria Cammarata, Meltemi, Roma 2008; The Screen of Enlightenment: Cinematographic Gazes on 18th Century, edited by Martial Poirson, Laurence Schifano, Voltaire Foundation, Oxford, 2009.

21. Michael Fried, Why Photography Matters as Art as never before, Yale University Press, New Haven-London, $2008,26$.

22. Denis Diderot, Letter on the Deaf and Dumb, ibid., Diderot's Early Philosophical Works, edited by Margaret Emily Jourdain, Open Court, Harvard, 1911.

23. Konrad Fiedler, Essays on Art, edited by Gottfried Boehm, Fink, München, 1991, Vol. 2.

24. Ernst Cassirer, The Philosophy of Symbolic Forms. Vol. 4. The Metaphysics of Symbolic Forms, edited by John Michael Krois and Donald Philip Verene, translated by John Michael Krois, Yale University Press, New Haven-London, 1996. 
25. Gottfried Boehm and William Thomas Mitchell, Pictorial versus Iconic Turn: Two Letters, The Pictorial Turn, edited by Neal Curtis, Routledge, London \& New York, 2010, 20. The first edition of the letter exchange between Boehm and Mitchell was published in: Questions on Images, edited by Hans Belting, Fink, München, 2007, 27-46. Keith Moxey, "Visual Studies and the Iconic Turn,” in Journal of Visual Culture, 7.2, August 2008, 131-46; “Iconic Turn and Social Reflection,” edited by Georges Didi-Huberman and Bernd Stiegler, Trivium. French-German Revue of Humanities and Social Science, 1, 2008; Focus, edited by Pietro Conte and Michele Di Monte, Lebenswelt. Aesthetics and Philosophy of Experience, 2, 2012, 118-218. Martin Jay's proposal to define a "Visual Turn:” Martin Jay, “That Visual Turn,” Journal of Visual Culture, 1, April 2002, 87-92.

26. Michele Cometa, "Postfazione,” William J. Thomas Mitchell, Pictorial Turn. Essays on Visual Culture, edited by Michele Cometa, due punti Edizioni, Palermo, 2008, 203 (my translation).

27. William Thomas Mitchell, The Pictorial Turn, 13.

28. Ibid., “The Obscure Object of Visual Culture,” Journal of Visual Culture, 2.2, August 2003, 249-52.

29. Ibid., "Four Fundamental Concepts of Image Science,” Visual Literacy, edited by James Elkins, Routledge, New York, 2008, 11-30; ibid., Showing Seeing: A Critique of Visual Culture, 348-9.

30. Ibid., "The Unspeakable and the Unimaginable. Word and Image in a Time of Terror,” E. L. H., 72, $2005,291$.

31. Ibid., Showing Seeing: A Critique of Visual Culture, 342.

32. Ibid., Iconology. Text, Image, Ideology, University of Chicago Press, Chicago, 1987; Martin Jay, Downcast Eyes. The Denigration of Vision in XX Century French Thought, University of California Press, Berkeley, 1994.

33. Already in the volume edited by Hal Foster, Vision and Visuality, the very title traces both a clear-cut border and a dialectical correlation between the natural dimension of seeing and the cultural and historical dimension of visuality: "Although vision suggests sight as a physical operation, and visuality sight as a social fact, the two are not opposed as nature to culture: vision is social and historical too, and visuality involves the body and the psyche. Yet neither are they identical: here, the difference between the terms signals a difference within the visual—between the mechanism of sight and its historical technique, between the datum of vision and its discursive determinations-a difference, many differences, among how we see, how we are able, allowed, or made to see, and how we see this seeing or the unseen therein" (Hal Foster, "Preface," Vision and Visuality, edited by Hal Foster, Bay Press, Seattle, 1988, IX).

34. William Thomas Mitchell, Showing Seeing: A Critique of Visual Culture, 345.

35. Ibid.

36. Ibid., “There are no Visual Media,” Journal of Visual Culture, 4.2, August 2005, 264-5.

37. Ibid., Showing Seeing: A Critique of Visual Culture, 356.

38. Ibid., "There are no Visual Media," 265.

39. Ibid., The Pictorial Turn, Critical iconology also aims at completing and thoroughly investigate "the question of the spectator," i.e., the enquiry on the subject of vision, which is eluded or suspended in Panofsky's pages (ivi, 18). 